\title{
Minute ventilation/carbon dioxide production in congenital heart disease
}

\author{
Alfred Hager
}

\author{
Number 9 in the Series "Ventilatory efficiency and its clinical prognostic value in cardiorespiratory \\ disorders" \\ Edited by Pierantonio Laveneziana and Paolo Palange
}

Dept of Pediatric Congenital Heart Disease and Pediatric Cardiology, Deutsches Herzzentrum München, Technical University of Munich, Munich, Germany.

Corresponding author: Alfred Hager (hager@dhm.mhn.de)

Shareable abstract (@ERSpublications)

$V_{\mathrm{E}}^{\prime} / V^{\prime} \mathrm{CO}_{2}$ elevation is a common finding in patients with congenital heart disease. It can be used as a sign for right-to-left shunting, unilateral pulmonary stenosis, pulmonary hypertension and circulatory failure. It is predictive for clinical worsening. https://bit.ly/33gj3NQ

Cite this article as: Hager A. Minute ventilation/carbon dioxide production in congenital heart disease. Eur Respir Rev 2021; 30: 200178 [DOI: 10.1183/16000617.0178-2020].

Copyright (CERS 2021

This version is distributed under the terms of the Creative Commons Attribution NonCommercial Licence 4.0. For commercial reproduction rights and permissions contact permissions@ersnet.org

Received: 2 June 2020 Accepted: 17 Nov 2020

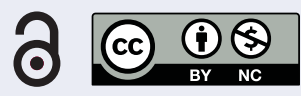

\section{Abstract}

This review summarises various applications of how ventilatory equivalent (ventilatory efficiency or better still ventilatory inefficiency) and the minute ventilation $\left(V_{\mathrm{E}}^{\prime}\right) /$ carbon dioxide production $\left(V_{\mathrm{CO}_{2}}^{\prime}\right)$ slope obtained from cardiopulmonary exercise testing (CPET) can be used in the diagnostic or prognostic workup of patients with congenital heart disease.

The field of congenital heart disease comprises not only a very heterogeneous patient group with various heart diseases, but also various conditions in different stages of repair, as well as the different residuals seen in long-term follow-up. As such, various physiologic disarrangements must be considered in the analysis of increased $V_{\mathrm{E}}^{\prime} / V_{\mathrm{CO}_{2}}^{\prime}$ slope from CPET in patients with congenital heart disease. In addition to congestive heart failure (CHF), cyanosis, unilateral pulmonary stenosis and pulmonary hypertension $(\mathrm{PH})$ provide the background for this finding. The predictive value of increased $V_{E}^{\prime} / V_{\mathrm{CO}_{2}}^{\prime}$ slope on prognosis seems to be more important in conditions where circulatory failure is associated with failure of the systemic ventricle. In cyanotic patients, those with Fontan circulation, or those with substantial mortality from arrhythmia, the impact of $V_{\mathrm{E}}^{\prime} / V_{\mathrm{CO}_{2}}^{\prime}$ on prognosis is not that important.

\section{Introduction}

The survival of patients with congenital heart defects has improved tremendously in the past decades. Nowadays, most of them reach adulthood despite various residuals limiting exercise capacity and quality of life $[1,2]$. Cardiopulmonary exercise testing (CPET) is increasingly used in the follow up of these patients in order to detect these residuals, as well as to quantify their importance. Furthermore, some variables obtained from CPET have turned out to predict survival and/or deterioration of disease.

Cardiology for congenital heart defects comprises very heterogeneous patient groups (with very different heart defects), various conditions in different stages of palliation and "repair", and different residuals in long-term follow-up. As such, many different kinds of physiologic disarrangement must be considered in the analysis of CPET (including the minute ventilation $\left(V_{\mathrm{E}}^{\prime}\right) /$ carbon dioxide production $\left(V_{\mathrm{CO}_{2}}^{\prime}\right)$ slope).

\section{Physiologic background}

The physiologic background of $V_{\mathrm{E}}^{\prime} / V_{\mathrm{CO}_{2}}^{\prime}$ is best described by the Bohr equation (figure 1) that has only a few requirements, as follows: 1 . there is no carbon dioxide in the inhaled air; 2 . the exhaled air is fully saturated with water; 3 . the barometric pressure is $760 \mathrm{mmHg}$; 4. the alveolar partial pressure of gases is 

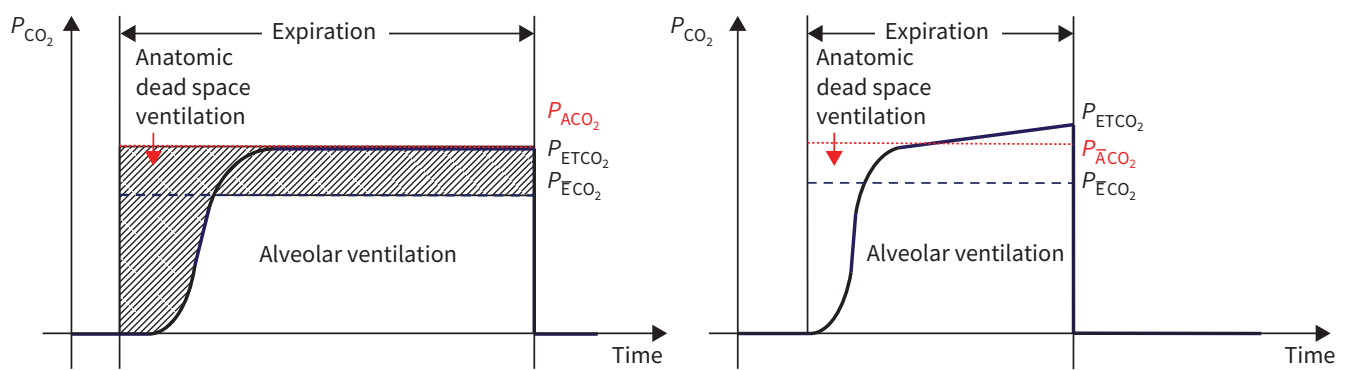

FIGURE 1 Carbon dioxide tension $\left(P_{\mathrm{CO}_{2}}\right)$ in the exhalation gas of healthy subjects at rest (left) and at exercise (right). $P_{\mathrm{ETCO}}$ : end-tidal carbon dioxide tension; $P_{\overline{\mathrm{E}} \mathrm{CO}_{2}}$ : mixed expiratory carbon dioxide tension; $P_{\mathrm{ACO}_{2}}$ : estimated alveolar carbon dioxide tension; $P_{\bar{A} \mathrm{AO}_{2}}$ : time-averaged alveolar carbon dioxide tension.

unique throughout the lung and does not change within the ventilatory cycle (such that equation 1 applies).

$$
\frac{V_{\mathrm{E}}^{\prime}}{V_{\mathrm{CO}_{2}}^{\prime}}=\frac{863}{P_{\bar{E}_{\mathrm{CO}_{2}}}}=\frac{863}{P_{\mathrm{ACO}_{2}} \cdot\left(1-V_{\mathrm{D}} / V_{\mathrm{T}}\right)}
$$

Here, $V_{\mathrm{E}}^{\prime}$ is under body temperature, pressure, fully saturated with water (BTPS) conditions and $V_{\mathrm{CO}_{2}}^{\prime}$ is under standard temperature, pressure, dry (STPD) conditions (at $863 \mathrm{mmHg}$ barometric pressure at body temperature, equivalent to $760 \mathrm{mmHg} \cdot(310 \mathrm{~K} / 273 \mathrm{~K}))$. Other parameters include mixed expiratory carbon dioxide tension $\left(P_{\overline{\mathrm{ECO}}}\right)$, alveolar carbon dioxide tension $\left(P_{\mathrm{ACO}_{2}}\right)$, dead space volume $\left(V_{\mathrm{D}}\right)$ and tidal volume $\left(V_{\mathrm{T}}\right)$.

In healthy subjects at rest, $P_{\mathrm{ACO}_{2}}$ can be estimated fairly well from end-tidal carbon dioxide tension $\left(P_{\mathrm{ETCO}_{2}}\right)$ or even more easy from arterial carbon dioxide tension $\left(P_{\mathrm{aCO}}\right)$. Therefore, EnGHOFF [3] proposed substituting $P_{\mathrm{ACO}}$ with $P_{\mathrm{aCO}}$ in the Bohr equation. However, this has tremendous effects on the definition of dead space, especially when the calculation is also used in subjects without uniform ventilation and without uniform alveolar partial pressures. The new calculation of dead space is nowadays referred as physiologic dead space and no longer resembles the anatomic dead space, as it includes all kinds of ventilation wasted in achieving a certain $P_{\mathrm{aCO}}$. This additional alveolar dead space comprises unperfused alveoli, wasted ventilation from ventilation $(V)$-perfusion $\left(Q^{\prime}\right)$ heterogeneity, an increased $V^{\prime} / Q^{\prime}$ ratio (as in circulatory failure), diffusion impairment and right-to-left shunt [4].

\section{Does end-tidal carbon dioxide tension help to differentiate the components of physiological dead} space?

In healthy subjects at rest, $P_{\mathrm{ACO}_{2}}$ can be estimated fairly well from $P_{\mathrm{ETCO}_{2}}$ and the calculated Bohr dead space resembles the anatomical dead space of the conducting airways (the upper airways, larynx and the tracheobronchial tree down to but excluding the acini) reasonably well [4]. There is very little shunting by bronchial and Thebesian veins and the arterial-end-tidal carbon dioxide tension difference $\left(P_{\mathrm{a}-\mathrm{ETCO}_{2}}\right)$ is $<5 \mathrm{mmHg}$. However, $P_{\mathrm{a}-\mathrm{ETCO}}$ increases as $P_{\mathrm{ACO}_{2}}$ starts to oscillate with breathing (even with very slow breathing and a high $V_{\mathrm{T}}$ ) and $P_{\mathrm{aCO}}$, represents only mean alveolar and not end-tidal $P_{\mathrm{ACO}_{2}}$. On the other hand, very quick and shallow breathing causes expiratory carbon dioxide tension $\left(P_{\mathrm{CO}_{2}}\right)$ to not reach the alveolar plateau [5].

At exercise there is so much carbon dioxide delivered from the working muscles to the alveoli that the oscillation of $P_{\mathrm{ACO}_{2}}$ increases. In exercising healthy subjects, $P_{\mathrm{a}-\mathrm{ETCO}}$ exceeds $P_{\mathrm{aCO}}$ with a $P_{\mathrm{a}-\mathrm{ETCO}_{2}}$ value of $-4 \mathrm{mmHg}$ (figure 2) [6,7]. On the other hand, patients with ventilatory restriction have a high ventilatory rate together with a low $V_{\mathrm{T}}$ that reduces end-tidal $P_{\mathrm{a}-\mathrm{ETCO}_{2}}$. Otherwise, patients with severely obstructed and little ventilated lung units have a continuous high inflow of additional carbon dioxide to the expiratory gas. At the end of expiration there is still efflux from these poorly ventilated regions, such that $P_{\mathrm{ETCO}_{2}}$ is extraordinarily high compared to $P_{\overline{\mathrm{ECO}}}$ [7, 8]. This reduced ratio of $P_{\overline{\mathrm{ECO}}} / P_{\mathrm{ETCO}_{2}}$ seems to be pathognomonic for severe bronchial constriction, especially at rest $[7,8]$.

\section{Ventilatory inefficiency}

According to the Enghoff modification of the Bohr equation, ventilatory inefficiency (elevated $V_{\mathrm{E}}^{\prime} / V_{\mathrm{CO}_{2}}^{\prime}$ ) is due either to decreased $P_{\mathrm{aCO}}$ (such as by voluntary hyperventilation or increased ventilatory drive by 

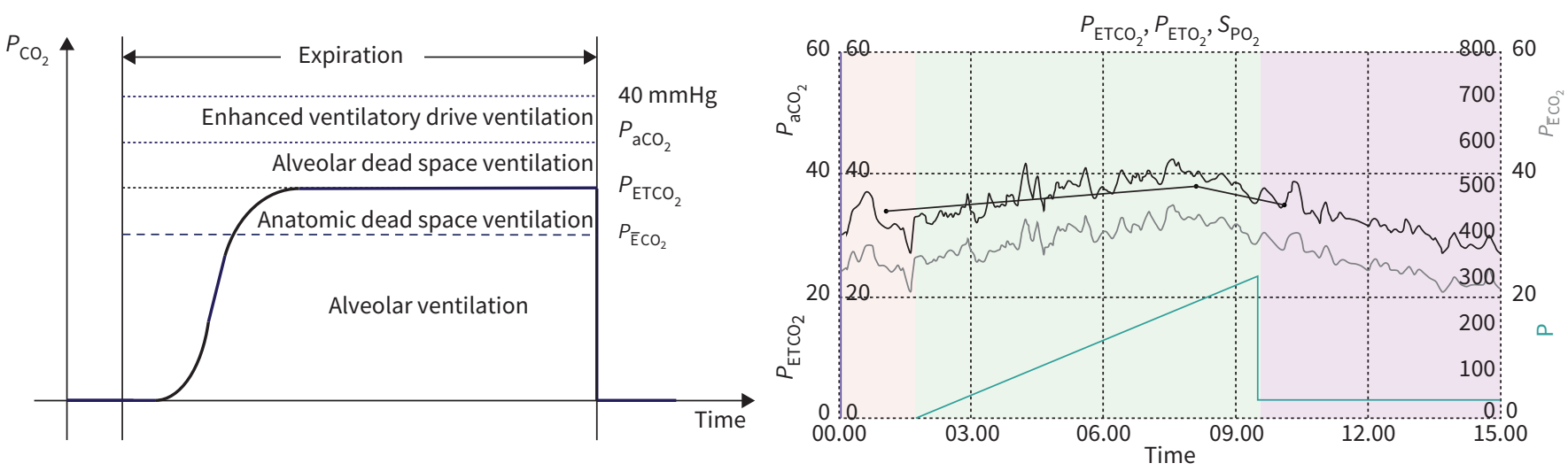

FIGURE 2 Rough interpretation of an elevated ventilatory equivalent (minute ventilation $\left(V_{\mathrm{E}}^{\prime}\right) /$ carbon dioxide production $\left(V^{\prime} \mathrm{cO}_{2}\right)$ ) with decreased mixed expiratory carbon dioxide tension $\left(P_{\overline{\mathrm{ECO}}}\right)$. The physiologic background is on the left with panel seven of a Wasserman nine-panel plot for a healthy subject on the right. $P_{\mathrm{CO}_{2}}$ : carbon dioxide tension; $P_{\mathrm{aCO}}$ : arterial carbon dioxide tension; $P_{\mathrm{ETCO}}$ : end-tidal carbon dioxide tension; $P_{\mathrm{ETO}}$ : end-tidal oxygen tension; $S_{\mathrm{pO}_{2}}$ : oxygen saturation measured by pulse oximetry.

metabolic acidosis, enhanced peripheral ergoreceptor reflex, or increased chemoreceptor sensitivity) or to elevated physiological dead space (alveolar or anatomical). However, equation 1 also shows that $V_{\mathrm{E}}^{\prime} / V^{\prime} \mathrm{CO}_{2}$ is just the reciprocal of $P_{\overline{\mathrm{E}} \mathrm{CO}_{2}}$ and, for a detailed analysis of the reasons for elevated $V_{\mathrm{E}}^{\prime} / V^{\prime} \mathrm{CO}_{2}$, it seems more reasonable to have a close look at $P_{\overline{\mathrm{E}} \mathrm{CO}}$ and determine the reasons for the low level of this parameter. $P_{\overline{\mathrm{E} C O}}$ resembles alveolar ventilation and must be analysed together with $P_{\mathrm{ETCO}}$ and $P_{\mathrm{aCO}}$. The relative contribution of enhanced ventilatory drive, as well as alveolar and anatomic dead space, can be estimated roughly according to figure 2, bearing in mind the difficulties in the interpretation of end-tidal $P_{\mathrm{ETCO}_{2}}$ discussed previously.

$\mathrm{V}^{\prime}{ }_{E} \mathrm{~N}^{\prime} \mathrm{CO}_{2}$ versus $\mathrm{V}_{E}^{\prime} \mathrm{N}^{\prime}{ }_{\mathrm{CO}_{2}}$ slope

The $V_{\mathrm{E}}^{\prime} / V^{\prime} \mathrm{CO}_{2}$ quotient can be calculated from every single breath throughout CPET. Usually, it declines hyperbolically at the beginning of the exercise test and reaches a minimum at the ventilatory compensation point, when lactic acidosis starts to increase ventilation independent of carbon dioxide production. On the other hand, the $V_{\mathrm{E}}^{\prime} / V_{\mathrm{CO}_{2}}^{\prime}$ slope is measured based on the whole exercise dataset, up to the ventilatory compensation point and is mathematically the asymptote of the $V_{\mathrm{E}}^{\prime} / V_{\mathrm{CO}_{2}}^{\prime}$ versus time curve that is almost touched at the ventilatory compensation point. Despite the smallest $V_{\mathrm{E}}^{\prime} / V^{\prime} \mathrm{CO}_{2}$ value throughout the test, the $V_{\mathrm{E}}^{\prime} / V_{\mathrm{CO}_{2}}^{\prime}$ at the ventilatory compensation point can be measured more reliably [9] and most metabolic carts already correct $V_{\mathrm{E}}^{\prime} / V_{\mathrm{CO}_{2}}^{\prime}$ for the dead space of the face mask. The $V_{\mathrm{E}}^{\prime} / V_{\mathrm{CO}_{2}}^{\prime}$ slope is much more extensively studied in cardiology, possibly because the slope can be measured even in incomplete exercise tests where the patient does not reach the ventilatory compensation point.

Some centres measure the $V_{\mathrm{E}}^{\prime} / V^{\prime} \mathrm{CO}_{2}$ slope over the entire exercise dataset, arguing that this excludes inter-observer variability and gives a better correlation to survival in heart failure with reduced ejection fraction [10]. However, it makes no sense physiologically to include such non-linear values after the ventilatory compensation point, as ventilatory drive is changed substantially at this moment by overt lactic acidosis. Furthermore, it makes the $V_{\mathrm{E}}^{\prime} / V^{\prime} \mathrm{CO}_{2}$ slope dependent on the grade of exhaustion at the end of exercise, as these few data points at the end of the test increase the calculated slope [7, 11].

Recently, there have also been publications on the $V_{\mathrm{E}}^{\prime} / V^{\prime} \mathrm{CO}_{2}$ intercept, which is the extrapolation of the $V_{\mathrm{E}}^{\prime} / V_{\mathrm{CO}_{2}}^{\prime}$ line to the y-axis. This intercept resembles the grade of $V_{\mathrm{E}}^{\prime} / V_{\mathrm{CO}_{2}}^{\prime}$ improvement at low to moderate exercise and his in turn translates to the improvement in anatomic dead space due to the rise in $V_{\mathrm{T}}$. In some patients with severe pulmonary hypertension $(\mathrm{PH})$, the intercept is at zero or even has a negative value, which means that there is no improvement or even a worsening in alveolar dead space at exercise [12]. This might be due to early hyperventilation, early failure of the circulation to maintain adequate lung perfusion or increasing local ventilation perfusion heterogeneity in these patients.

\section{$V^{\prime}{ }_{\mathrm{E}} / V^{\prime}{ }_{\mathrm{CO}}$ to detect diagnostic details in congenital heart disease}

\section{Right-to-left shunt}

Only a small number of all congenital heart defects are cyanotic at birth. In one group, this cyanosis is due to a shunt defect combined with a blood flow obstruction downstream to (or in) the lungs. A second group 
has a malconnection on the veno-atrial level (e.g. total anomalous pulmonary venous return), the atrioventricular level (e.g. a double-inlet left ventricle), or the ventriculo-arterial level (e.g. transposition of the great arteries) that directs venous blood into the aorta. A third group consists of those patients with a univentricular heart, where one ventricle is serving both the pulmonary and systemic circulation (e.g. hypoplastic left-heart syndrome) unless Fontan circulation is established. A fourth group has intrapulmonary shunts (e.g. Osler's disease). Later in life a fifth group appears, namely Eisenmenger patients (who are born with a left-to-right shunt). The initial hyperperfusion of the lung leads to pulmonary vascular disease and finally shunt reversal. All these patients are cyanotic at rest. Oxygen saturation measured by pulse oximetry $\left(S_{\mathrm{pO}_{2}}\right)$ declines further at exercise $[12,13]$ when mixed venous blood (and shunting blood) becomes more desaturated and/or the pulmonary obstruction reaches a flow limitation. The nadir of $S_{\mathrm{pO}_{2}}$ is about $30 \mathrm{~s}$ after exercise (personal observation).

$V_{\mathrm{E}}^{\prime} / V_{\mathrm{CO}_{2}}^{\prime}$ slope is strongly and inversely associated with resting $S_{\mathrm{pO}_{2}}$ in all congenital heart disease [11], as well as in cyanotic patients with and without $\mathrm{PH}[12,13]$. (Cyanosis has an additional effect on the $V_{\mathrm{E}}^{\prime} / V_{\mathrm{CO}_{2}}^{\prime}$ slope in patients with $\left.\mathrm{PH}[11]\right)$. As cyanosis is nowadays detected by pulse oximetry, the sensitivity of which has improved tremendously following the introducing of the forehead sensor and software eliminating movement artifacts, pulse oximetry should never be omitted on CPET of patients with congenital heart defects.

\section{Exercise-induced right-to-left shunt}

Shunts at the venous, atrial, ventricular or arterial level are usually left-to-right shunts. When the right heart fails or there is an extraordinary rise in pulmonary arterial pressure (PAP) (e.g. PH), a fixed right-ventricular outflow tract stenosis (e.g. pulmonary valve stenosis), or an increase in severe tricuspid regurgitation (sometimes seen in the Ebstein anomaly), these shunts flip to a right-to-left configuration. Even if there is no shunt at rest, these conditions can also open a foramen ovale (PFO) whenever right-atrial pressure exceeds left-atrial pressure [14].

In patients with Fontan circulation (e.g. a univentricular heart with direct connection of the caval veins to the pulmonary artery without the right ventricle), even small increases in PAP can lead to veno-venous fistulae with increasing right-to-left shunt.

When the exercise-induced shunt appears on CPET, there is a sudden rise in $V_{\mathrm{E}}^{\prime} / V_{\mathrm{CO}_{2}}^{\prime}, V_{\mathrm{E}}^{\prime}$ /oxygen uptake $\left(V_{\mathrm{O}_{2}}^{\prime}\right)$, respiratory exchange ratio (RER) and end-tidal oxygen tension $\left(P_{\mathrm{ETO}}\right)$, combined with a sudden decrease in $P_{\mathrm{ETCO}_{2}}$ and $S_{\mathrm{pO}_{2}}$ [14]. In patients with an early-appearing shunt the findings may, with the exception of the decrease in $S_{\mathrm{pO}_{2}}$, be similar to anxiety-induced hyperventilation [14]. In patients with a shunt only at high workload, the anaerobic threshold and ventilatory compensation point can no longer be determined and it appears, very pronouncedly, as if these two thresholds are reached at the same time point combined with the beginning of decline in $S_{\mathrm{pO}_{2}}$. In such patients, at the end of the exercise test, all typical findings for the exercise-induced shunt return quickly to the values seen before the opening of the shunt [14].

Finally, it should be mentioned that, in young healthy subjects, heavy exercise with very high pulmonary blood flow and elevated pulmonary blood pressure itself causes alveolar capillary dilatation with a diffusion-perfusion mismatch that ends up in a decline of $S_{\mathrm{pO}_{2}}$ at the peak of exercise [15-17]. Again, cyanosis is nowadays primarily detected by pulse oximetry, but should be considered in the analysis of elevated $V_{\mathrm{E}}^{\prime} / V_{\mathrm{CO}_{2}}^{\prime}$ slope with all the other changes with cyanosis.

\section{Unilateral pulmonary stenosis}

Many congenital heart defects are associated with unifocal or multifocal pulmonary artery branch stenoses. Patients with Fallot tetralogy are prone to a stenosis at the former origin of the arterial duct slightly distal to the origin of the left pulmonary artery. This is usually patched at surgical repair but might also appear later, even after retreatment by interventional balloon dilatation or stent implantation. In patients with pulmonary atresia with ventricular septal defect and multiple aorto-pulmonary collateral arteries, these aorto-pulmonary collaterals tend to become stenotic even when they are unifocalised and connected to the right-ventricular outflow tract. They often end up in multifocal central and peripheral stenoses and are difficult to treat because of their high recurrence rate.

There are also post-surgical conditions that might end up with pulmonary branch stenosis. Surgical shunts onto the pulmonary arteries are performed in many patients with complex congenital defects to stabilise pulmonary blood flow until surgical repair or to progress to a univentricular circulation according to 
Fontan. When these shunts are connected to one of the pulmonary arteries, there is the risk of stenosis after surgical closure of the shunt.

Another important example is transposition of the great arteries that is nowadays treated by an early arterial switch operation with the Lecompt manoeuvre. This is a translocation of the pulmonary bifurcation anterior to the ascending aorta with the risk of future pulmonary stenosis in one or both pulmonary arteries.

In Fallot patients [18], as well as in patients subsequent to arterial switch repair for transposition [19], it has been shown that an abnormal right-to-left ratio of pulmonary blood flow (obtained by cardiac magnetic resonance) has an increased $V_{\mathrm{E}}^{\prime} / V_{\mathrm{CO}_{2}}^{\prime}$ slope compared to patients with balanced pulmonary blood flow. This increased $V_{\mathrm{E}}^{\prime} / V_{\mathrm{CO}_{2}}^{\prime}$ slope improves after ballooning the stenosis [20] or after stenting [21]. The decline of the $V_{E}^{\prime} / V_{\mathrm{CO}_{2}}^{\prime}$ slope after treatment is directly associated with improvement in pulmonary blood flow ratio [20, 21]. A stenosis of the main pulmonary artery does not cause any perfusion mismatch and, therefore, shows no elevation in $V_{\mathrm{E}}^{\prime} / V_{\mathrm{CO}_{2}}^{\prime}$ slope [22].

\section{Pulmonary hypertension}

All classes of PH can occur in patients with congenital heart defects (table 1), and both diagnosis and treatment have been extensively reported upon recently [24]. From idiopathic pulmonary arterial hypertension (PAH) [25] and left-heart failure $\mathrm{PH}[26,27]$, we know that $V_{\mathrm{E}}^{\prime} / V_{\mathrm{CO}_{2}}^{\prime}$ and $P_{\mathrm{ETCO}}$ are closely associated with $\mathrm{PAH}$ and this also holds true in congenital heart disease [28]. After vasodilator therapy, $V_{\mathrm{E}}^{\prime} / V_{\mathrm{CO}_{2}}^{\prime}$ improves in Eisenmenger patients [29]; however, specificity is too low to use CPET and especially $V_{\mathrm{E}}^{\prime} / V_{\mathrm{CO}_{2}}^{\prime}$ slope as a screening tool for $\mathrm{PH}$ in patients with congenital heart defects [28].

Acyanotic patients with congenital heart disease and $\mathrm{PH}$ are rare, and it should be assumed that $V_{\mathrm{E}}^{\prime} / V_{\mathrm{CO}_{2}}^{\prime}$ reacts similarly to elevated pulmonary vascular resistance or left-heart failure. Furthermore, it should be expected that as the number of elderly patients with congenital heart disease continues to rise, the number of patients with left-heart failure especially should also increase over the coming decades [30, 31].

\section{Enhanced ergoreceptor/chemoreceptor reflex}

In patients with acquired congestive heart failure (CHF) there are often changes in ventilation pattern. At night there might be sleep apnoea, while at exercise one can detect exercise-induced oscillatory ventilation as well as an enhanced ventilatory drive measured as low $P_{\mathrm{aCO}}$. In congenital cardiology however, cyanotic patients without heart failure show minimal nocturnal dips in oxygen saturation (so no sleep apnoea) [32]. This might be in contrast to patients with circulatory failure, as periodic breathing is only described in two acyanotic patients with right-heart failure [33]. There are only a few descriptions of exercise oscillatory ventilation in Fontan patients [34, 35]; however, they are contradictory concerning prognostic capabilities.

Concerning the impact of ventilatory drive on elevated $V_{E}^{\prime} / V_{\mathrm{CO}_{2}}^{\prime}$, there are only a few studies analysing exactly what is contributing to alveolar dead space or enhanced ventilation and most of these studies do not report an arterial blood gas analysis (i.e. $P_{\mathrm{aCO}_{2}}$ ). Even those few that do are not consistent, as some report slightly reduced $P_{\mathrm{aCO}}$ at rest which normalises on exercise [13, 36], while others report usually lowered $P_{\mathrm{aCO}_{2}}$ in Eisenmenger patients [37], both with [36] and without [37] an impact on survival.

$V^{\prime} / V^{\prime}{ }_{\mathrm{CO}_{2}}$ to estimate prognosis in congenital heart disease

Early studies looked for risk factors from CPET in the whole cohort of congenital heart disease. $V_{\mathrm{E}}^{\prime} / V_{\mathrm{CO}_{2}}^{\prime}$ is associated with functional class [38] and can predict survival [38, 39] independently from New York Heart Association (NYHA) class [38], although the importance of the risk factor is low compared to resting $S_{\mathrm{pO}_{2}}$, peak $V_{\mathrm{O}_{2}}^{\prime}$, age, or heart rate reserve [39, 40]. However, these types of study do not help too much as, firstly, we already know that the patient group with the worst cyanosis, most severe $\mathrm{PH}$ and the least exercise capacity, which is the Eisenmenger group, has the worst prognosis compared to the other less disabled patients with congenital heart disease. Secondly, the mixture of various different diagnoses and conditions might dilute the results [40] and, as such, studies on isolated patient groups with similar conditions are needed to evaluate the additional prognostic importance of certain biomarkers (such as CPET variables) beyond simple parameters like diagnosis, age, body mass index, resting $S_{\mathrm{pO}_{2}}$ and functional class.

\section{Cyanotic congenital heart disease and Eisenmenger's disease}

In cyanotic patients with congenital heart disease, death was not only attributed to heart failure but also to sudden death (e.g. arrhythmia, lung haemorrhage, dissection of ascending aorta and cerebral accidents) [41, 42] 
TABLE 1 Types of pulmonary hypertension (PH) according to European Society of Cardiology (ESC)/European Respiratory Society (ERS) guidelines [23]; those associated with congenital heart defects are marked in bold

\section{Classification}

1

1.1

1.2

1.2 .1

1.2 .2

1.3

1.4

1.4.1

1.4 .2

1.4 .3

1.4 .4

1.4.4.1

1.4.4.2

1.4.4.3

1.4.4.4

1.4 .5

$1^{\prime}$

$1^{\prime} .1$

$1^{\prime} .2$

$1^{\prime} \cdot 2.1$

$1^{\prime} .2 .2$

$1^{\prime} .3$

$1^{\prime} .4$

$1^{\prime} .4 .1$

$1^{\prime} .4 .2$

$1^{\prime \prime}$

2

2.1

2.2

2.3

2.4

2.5

3

3.1

3.2

3.3

3.4

3.5

3.6

3.7

4

4.1

4.2

4.2 .1

4.2.2

4.2 .3

4.2 .4

4.2 .5

5

5.1

5.2

5.3

5.4

\section{Description}

$\mathrm{PAH}$

Idiopathic

Heritable

BMPR2 mutation

Other mutations

Drug and toxin induced

Associated with:

Connective tissue disease

HIV infection

Portal hypertension

Congenital heart disease

Eisenmenger's syndrome

PAH associated with prevalent systemic to pulmonary shunt

PAH with small/coincidental defects

$\mathrm{PAH}$ after defect correction

Schistosomiasis

Pulmonary veno-occlusive disease and/or pulmonary capillary haemangiomatosis

Idiopathic

Heritable

EIF2AK4 mutation

Other mutations

Drug, toxin and radiation induced

Associated with:

Connective tissue disease HIV infection

Persistent $\mathrm{PH}$ of the newborn

$\mathrm{PH}$ due to left-heart disease

Left-ventricular systolic dysfunction

Left-ventricular diastolic dysfunction

Valvular disease, obstruction and congenital cardiomyopathy

Congenital/acquired left-heart inflow/outflow tract obstruction and congenital cardiomyopathies

Congenital/acquired pulmonary vein stenosis

$\mathrm{PH}$ due to lung disease and/or hypoxia

COPD

ILD

Other pulmonary diseases with mixed restrictive and obstructive patterns

SDB

Alveolar hypoventilation disorders

Chronic exposure to high altitude

Developmental lung diseases

CTEPH and other pulmonary artery obstructions

CTEPH

Other pulmonary artery obstructions

Angiosarcoma

Other intravascular tumours

Arteritis

Congenital pulmonary arterial stenoses

Parasites (hydatidosis)

$\mathrm{PH}$ with unclear and/or multifactorial mechanisms

Haematological disorders (chronic haemolytic anaemia, myeloproliferative disorders and splenectomy)

Systemic disorders (sarcoidosis, pulmonary histiocytosis, lymphangioleiomyomatosis and neurofibromatosis)

Metabolic disorders (glycogen storage disease, Gaucher's disease and thyroid disorders)

Others (pulmonary tumoral thrombothic microangiopathy, fibrosing mediastinitis, chronic renal failure (with/without dialysis) and segmental PH)

PAH: pulmonary arterial hypertension; BMPR2: bone morphogenetic protein receptor type 2; EIF2AK4: eukaryotic translation initiation factor 2 alpha kinase 4; COPD: chronic obstructive pulmonary disease; ILD: interstitial lung disease; SDB: sleep disordered breathing; CTEPH: chronic thromboembolic pulmonary hypertension. 
and other organ failure [24]. Despite peak $V_{\mathrm{O}_{2}}^{\prime}$ having an important impact on survival, $V_{\mathrm{E}}^{\prime} / V_{\mathrm{CO}_{2}}^{\prime}$ was not related to outcome [39].

\section{Univentricular heart with Fontan circulation}

Exercise parameters have an important prognostic value in patients with univentricular heart and Fontan circulation [43]. Despite a substantial elevation of both $V_{\mathrm{E}}^{\prime} / V_{\mathrm{CO}_{2}}^{\prime}$ slope and $V_{\mathrm{E}}^{\prime} / V_{\mathrm{CO}_{2}}^{\prime}$, these values were not predictive for survival or transplantation [44]. $V_{\mathrm{E}}^{\prime} / V_{\mathrm{CO}_{2}}^{\prime}$ only predicts hospitalisation and various morbidities [44, 45].

\section{Fallot tetralogy}

In this patient group, $V_{\mathrm{E}}^{\prime} / V_{\mathrm{CO}_{2}}^{\prime}$ is elevated mainly because of pulmonary branch stenosis [18] and a failing left ventricle. Possibly due to a high rate of sudden arrhythmic deaths, $V_{\mathrm{E}}^{\prime} / V_{\mathrm{CO}_{2}}^{\prime}$ is not an additive risk factor for QRS duration and peak $V_{\mathrm{O}_{2}}^{\prime}$ in predicting survival [46]. However, it does predict event-free survival independently from QRS duration and peak $V_{\mathrm{O}_{2}}^{\prime}[46-48]$.

Transposition of the great arteries after atrial redirection according to Mustard or Senning

In patients with transposition of the great arteries, survival after atrial redirection depends mainly on arrythmia or right-ventricular (systemic) failure, whereas reinterventions were performed for baffle stenosis or leakage [49]. The $V_{E}^{\prime} / V_{\mathrm{CO}_{2}}^{\prime}$ slope is predictive for survival without emergency hospital admissions [50].

\section{Conclusions}

It is inappropriate to summarise over various congenital heart diseases and the various conditions of such patients throughout life. The predictive value of increased $V_{\mathrm{E}}^{\prime} / V_{\mathrm{CO}_{2}}^{\prime}$ slope on prognosis seems to be more important in conditions where circulatory failure is associated with failure of the systemic ventricle. In cyanotic patients, patients with Fontan circulation, or those with substantial mortality from arrhythmia, the impact of $V_{\mathrm{E}}^{\prime} / V_{\mathrm{CO}_{2}}^{\prime}$ on prognosis is not that important. However, the $V_{\mathrm{E}}^{\prime} / V_{\mathrm{CO}_{2}}^{\prime}$ slope is an excellent predictor of clinical deterioration, unscheduled hospitalisation or other non-fatal clinical events both independently and in addition to peak $V_{\mathrm{O}_{2}}^{\prime}$.

Provenance: Commissioned article, peer reviewed.

Previous articles in this series: No. 1: Laveneziana P, Di Paolo M, Palange P. The clinical value of cardiopulmonary exercise testing in the modern era. Eur Respir Rev 2021; 30: 200187. No. 2: Agnostoni P, Sciomer S, Palermo P, et al. Minute ventilation/carbon dioxide production in chronic heart failure. Eur Respir Rev 2021; 30: 200141. No. 3: Watson M, Ionescu MF, Sylvester K, et al. Minute ventilation/carbon dioxide production in patients with dysfunctional breathing. Eur Respir Rev 2021; 30: 200182. No. 4: Ward SA. Ventilation/carbon dioxide output relationships during exercise in health. Eur Respir Rev 2021; 30: 200160. No. 5: Collins SÉ, Phillips DB, Brotto AR, et al. Ventilatory efficiency in athletes, asthma and obesity. Eur Respir Rev 2021; 30: 200206. No. 6: Schaegger MR, Guenette JA, Jensen D. Impact of ageing and pregnancy on the minute ventilation/carbon dioxide production response to exercise. Eur Respir Rev 2021; 30: 200225. No. 7: Weatherald J, Philipenko B, Montani D, et al., Ventilatory efficiency in pulmonary vascular diseases. Eur Respir Rev 2021; 30: 200214. No. 8: Neder JA, Berton DC, Phillips DB, et al. Exertional ventilation/carbon dioxide output relationship in COPD: from physiological mechanisms to clinical applications. Eur Respir Rev 2021; 30: 200190.

Conflict of interest: A. Hager reports personal fees from Actelion Pharmaceuticals and Bayer AG, outside the submitted work.

\section{References}

1 Muller J, Hess J, Hager A. Sense of coherence, rather than exercise capacity, is the stronger predictor to obtain health-related quality of life in adults with congenital heart disease. Eur J Prev Cardiol 2014; 21: 949-955.

2 Gratz A, Hess J, Hager A. Self-estimated physical functioning poorly predicts actual exercise capacity in adolescents and adults with congenital heart disease. Eur Heart J 2009; 30: 497-504.

3 Enghoff H. [Volumen inefficax. Bemerkungen zur Frage des schädlichen Raumes. Upsala Laekarefoeren]. Foerh 1938; 44: 191-218.

4 Robertson HT. Dead space: the physiology of wasted ventilation. Eur Respir J 2015; 45: 1704-1716.

5 Jones NL, Robertson DG, Kane JW. Difference between end-tidal and arterial $P_{\mathrm{CO} 2}$ in exercise. J Appl Physiol Respir Environ Exerc Physiol 1979; 47: 954-960.

6 Wasserman K, Van Kessel AL, Burton GG. Interaction of physiological mechanisms during exercise. J Appl Physiol 1967; 22: 71-85. 
7 Wasserman K, Hansen JE, Sue DY, et al. Principles of exercise testing and interpretation. 5th Edn. Philadelphia, Lippincott Williams \& Wilkins, 2012; pp. 572.

8 Hansen JE, Ulubay G, Chow BF, et al. Mixed-expired and end-tidal $\mathrm{CO}_{2}$ distinguish between ventilation and perfusion defects during exercise testing in patients with lung and heart diseases. Chest 2007; 132: 977-983.

9 Sun XG, Hansen JE, Garatachea N, et al. Ventilatory efficiency during exercise in healthy subjects. Am J Respir Crit Care Med 2002; 166: 1443-1448.

10 Tabet JY, Beauvais F, Thabut G, et al. A critical appraisal of the prognostic value of the $V_{\mathrm{E}} / V_{\mathrm{CO} 2}$ slope in chronic heart failure. Eur J Cardiovasc Prev Rehabil 2003; 10: 267-272.

11 Dimopoulos K, Okonko DO, Diller GP, et al. Abnormal ventilatory response to exercise in adults with congenital heart disease relates to cyanosis and predicts survival. Circulation 2006; 113: 2796-2802.

12 Muller J, Hess J, Hager A. Exercise performance and quality of life is more impaired in Eisenmenger syndrome than in complex cyanotic congenital heart disease with pulmonary stenosis. Int J Cardiol 2011; 150: 177-181.

13 Glaser S, Opitz CF, Bauer U, et al. Assessment of symptoms and exercise capacity in cyanotic patients with congenital heart disease. Chest 2004; 125: 368-376.

14 Sun XG, Hansen JE, Oudiz RJ, et al. Gas exchange detection of exercise-induced right-to-left shunt in patients with primary pulmonary hypertension. Circulation 2002; 105: 54-60.

15 Norris HC, Mangum TS, Duke JW, et al. Exercise- and hypoxia-induced blood flow through intrapulmonary arteriovenous anastomoses is reduced in older adults. J Appl Physiol (1985) 2014; 116: 1324-1333.

16 Laurie SS, Elliott JE, Goodman RD, et al. Catecholamine-induced opening of intrapulmonary arteriovenous anastomoses in healthy humans at rest. J Appl Physiol (1985) 2012; 113: 1213-1222.

17 Lovering AT, Haverkamp HC, Romer LM, et al. Transpulmonary passage of 99mTc macroaggregated albumin in healthy humans at rest and during maximal exercise. J Appl Physiol (1985) 2009; 106: 1986-1992.

18 Rhodes J, Dave A, Pulling MC, et al. Effect of pulmonary artery stenoses on the cardiopulmonary response to exercise following repair of tetralogy of Fallot. Am J Cardiol 1998; 81: 1217-1219.

19 Giardini A, Khambadkone S, Taylor A, et al. Effect of abnormal pulmonary flow distribution on ventilatory efficiency and exercise capacity after arterial switch operation for transposition of great arteries. Am J Cardiol 2010; 106: 1023-1028.

20 Sutton NJ, Peng L, Lock JE, et al. Effect of pulmonary artery angioplasty on exercise function after repair of tetralogy of Fallot. Am Heart J 2008; 155: 182-186.

21 Hiremath G, Qureshi AM, Prieto LR, et al. Balloon angioplasty and stenting for unilateral branch pulmonary artery stenosis improve exertional performance. JACC Cardiovasc Interv 2019; 12: 289-297.

22 Baggen VJ, Driessen MM, Meijboom FJ, et al. Main pulmonary artery area limits exercise capacity in patients long-term after arterial switch operation. J Thorac Cardiovasc Surg 2015; 150: 918-925.

23 Galie N, Humbert M, Vachiery JL, et al. 2015 ESC/ERS guidelines for the diagnosis and treatment of pulmonary hypertension. Eur Heart J 2016; 37: 67-119.

24 Kaemmerer H, Apitz C, Brockmeier K, et al. Pulmonary hypertension in adults with congenital heart disease: updated recommendations from the Cologne Consensus Conference 2018. Int J Cardiol 2018; 272S: 79-88.

25 Yasunobu $\mathrm{Y}$, Oudiz RJ, Sun XG, et al. End-tidal $P_{\mathrm{CO} 2}$ abnormality and exercise limitation in patients with primary pulmonary hypertension. Chest 2005; 127: 1637-1646.

26 Guazzi M, Cahalin LP, Arena R. Cardiopulmonary exercise testing as a diagnostic tool for the detection of left-sided pulmonary hypertension in heart failure. J Card Fail 2013; 19: 461-467.

27 Guazzi M, Labate V, Cahalin LP, et al. Cardiopulmonary exercise testing reflects similar pathophysiology and disease severity in heart failure patients with reduced and preserved ejection fraction. Eur J Prev Cardiol 2014; 21: 847-854.

28 Muller J, Heck PB, Ewert P, et al. Noninvasive screening for pulmonary hypertension by exercise testing in congenital heart disease. Ann Thorac Surg 2017; 103: 1544-1549.

29 Yang-Ting S, Aboulhosn J, Sun XG, et al. Effects of pulmonary vasodilator therapy on ventilatory efficiency during exercise in adults with Eisenmenger syndrome. Congenit Heart Dis 2011; 6: 139-146.

30 Tutarel O. Acquired heart conditions in adults with congenital heart disease: a growing problem. Heart 2014; 100: $1317-1321$.

31 Tutarel O, Kempny A, Alonso-Gonzalez R, et al. Congenital heart disease beyond the age of 60: emergence of a new population with high resource utilization, high morbidity, and high mortality. Eur Heart J 2014; 35: 725-732.

32 Legault S, Lanfranchi P, Montplaisir J, et al. Nocturnal breathing in cyanotic congenital heart disease. Int J Cardiol 2008; 128: 197-200.

33 Georgiadou P, Babu-Narayan SV, Francis DP, et al. Periodic breathing as a feature of right heart failure in congenital heart disease. Heart 2004; 90: 1075-1076.

34 Muneuchi J, Joo K, Yamamura K, et al. Exertional oscillatory ventilation during cardiopulmonary exercise test in Fontan patients with total cavopulmonary connection. Pediatr Cardiol 2009; 30: 452-457. 
35 Nathan AS, Loukas B, Moko L, et al. Exercise oscillatory ventilation in patients with Fontan physiology. Circ Heart Fail 2015; 8: 304-311.

36 Callegari G, D'Armini AM, Baiardi P, et al. Predictors of mortality in patients with Eisenmenger syndrome and admission to the lung transplantation waiting list. Monaldi Arch Chest Dis 2004; 61: 199-202.

37 Broberg CS, Van Woerkom RC, Swallow E, et al. Lung function and gas exchange in Eisenmenger syndrome and their impact on exercise capacity and survival. Int J Cardiol 2014; 171: 73-77.

38 Bredy C, Ministeri M, Kempny A, et al. New York Heart Association (NYHA) classification in adults with congenital heart disease: relation to objective measures of exercise and outcome. Eur Heart J Qual Care Clin Outcomes 2018; 4: 51-58.

39 Inuzuka R, Diller GP, Borgia F, et al. Comprehensive use of cardiopulmonary exercise testing identifies adults with congenital heart disease at increased mortality risk in the medium term. Circulation 2012; 125: 250-259.

40 Rhodes J. Cardiopulmonary exercise testing in adults with congenital heart disease: can we prognosticate and improve prognosis? Circulation 2012; 125: 210-211.

41 Diller GP, Dimopoulos K, Broberg CS, et al. Presentation, survival prospects, and predictors of death in Eisenmenger syndrome: a combined retrospective and case-control study. Eur Heart J 2006; 27: 1737-1742.

42 Niwa K, Perloff JK, Kaplan S, et al. Eisenmenger syndrome in adults: ventricular septal defect, truncus arteriosus, univentricular heart. J Am Coll Cardiol 1999; 34: 223-232.

43 Udholm S, Aldweib N, Hjortdal VE, et al. Prognostic power of cardiopulmonary exercise testing in Fontan patients: a systematic review. Open Heart 2018; 5: e000812.

44 Diller GP, Giardini A, Dimopoulos K, et al. Predictors of morbidity and mortality in contemporary Fontan patients: results from a multicenter study including cardiopulmonary exercise testing in 321 patients. Eur Heart J 2010; 31: 3073-3083.

45 Egbe AC, Driscoll DJ, Khan AR, et al. Cardiopulmonary exercise test in adults with prior Fontan operation: the prognostic value of serial testing. Int J Cardiol 2017; 235: 6-10.

46 Muller J, Hager A, Diller GP, et al. Peak oxygen uptake, ventilatory efficiency and QRS-duration predict event free survival in patients late after surgical repair of tetralogy of Fallot. Int J Cardiol 2015; 196: 158-164.

47 Giardini A, Specchia S, Tacy TA, et al. Usefulness of cardiopulmonary exercise to predict long-term prognosis in adults with repaired tetralogy of Fallot. Am J Cardiol 2007; 99: 1462-1467.

48 Buys R, Van De Bruaene A, De Meester P, et al. Predictors of mid-term event-free survival in adults with corrected tetralogy of Fallot. Acta Cardiol 2012; 67: 415-421.

49 Cuypers JA, Eindhoven JA, Slager MA, et al. The natural and unnatural history of the Mustard procedure: long-term outcome up to 40 years. Eur Heart J 2014; 35: 1666-1674.

50 Giardini A, Hager A, Lammers AE, et al. Ventilatory efficiency and aerobic capacity predict event-free survival in adults with atrial repair for complete transposition of the great arteries. J Am Coll Cardiol 2009; 53: 1548-1555. 